\title{
Increased Production of Nitric Oxide in Coronary Arteries during Congestive Heart Failure
}

\author{
Brian O'Murchu, Virginia M. Miller, Mark A. Perrella, and John C. Burnett, Jr. \\ Cardiorenal Research Laboratory of the Division of Cardiovascular Diseases, Department of Surgery, and Department \\ of Physiology and Biophysics, Mayo Clinic and Foundation, Rochester, Minnesota 55905
}

\begin{abstract}
Experiments were designed to determine whether a heterogeneity of endothelium-dependent relaxations in arteries from different vascular beds exists in experimental congestive heart failure (CHF) and to determine the mediators of those responses. CHF was produced in dogs by rapid ventricular pacing for $15 \mathrm{~d}$. Rings of coronary, femoral, and renal arteries with and without endothelium from control and CHF dogs were suspended in organ chambers for measurement of isometric force. In arteries contracted with prostaglandin $F_{2}$ alpha, endothelium-dependent relaxations to BHT 920 (an alpha ${ }_{2}$-adrenergic agonist) were increased in coronary arteries from dogs with CHF (maximal relaxation: control $-15 \pm 9 \%$ vs CHF $-92 \pm 5 \%$; $n=5-6 ; P<0.05$ ), with a modest enhancement in renal arteries. Relaxations to adenosine diphosphate and the calcium ionophore were unchanged. Relaxations to BHT 920 in CHF were reduced by $\boldsymbol{N}^{\mathbf{G}}$ monomethyl-L-arginine (L-NMMA) and pertussis toxin but not by indomethacin. These data suggest that endothelium-dependent relaxations are affected heterogeneously in CHF. The enhanced response to alpha $a_{2}$-adrenergic agonists in the coronary artery is mediated by nitric oxide through a mechanism sensitive to inhibition by pertussis toxin. This selective increase in endothelium-dependent relaxations in the coronary artery may contribute to preserving coronary blood flow during CHF. (J. Clin. Invest. 1994. 93:165-171.) Key words: endothelium • vasodilatation • adrenergic function • coronary blood flow $\bullet$ guanine nucleotide-binding regulatory proteins
\end{abstract}

\section{Introduction}

While systemic vasoconstriction is a hallmark of severe chronic congestive heart failure (CHF), ${ }^{1}$ a preservation of coronary blood flow has been reported both in human and in experimental CHF (1-4). The role of endothelium in contributing to

Address correspondence to John C. Burnett, Jr., M.D., Cardiorenal Research Laboratory, Mayo Clinic, 200 First Street, SW, Rochester, MN 55905.

Received for publication 23 November 1992 and in revised form 24 August 1993.

1. Abbreviations used in this paper: $\mathrm{ANF}$, atrial natriuretic factor; $\mathrm{BHT}$ 920, 6-allyl-2-amino-5,6,7,8-tetrahydro-4H-thiazolo-(4,5-d)azepin dihydrochloride; $\mathrm{CHF}$, congestive heart failure; $\mathrm{CO}$, cardiac output; Gproteins, guanine nucleotide-binding regulatory proteins; Gi, G-proteins that inhibit; L-NMMA, $N^{\mathrm{G}}$ monomethyl-L-arginine; MAP, mean arterial pressure; NO, nitric oxide; PRA, plasma renin activity; RAP, right arterial pressure; SVR, systemic vascular resistance.

The Journal of Clinical Investigation, Inc.

Volume 93, January 1994, 165-171 altered vascular responses in CHF, however, remains controversial (5-9). Recent studies have suggested that enhanced endothelium-dependent relaxations to alpha ${ }_{2}$-adrenergic agonists in experimental CHF may serve as an important protective mechanism to maintain coronary blood flow (9). Specifically, recent investigations which examined alpha-adrenergic responses in isolated coronary arterial rings from dogs with and without pacing-induced CHF demonstrated an augmentation of endothelium-dependent relaxation to norepinephrine and the alpha $a_{2}$-adrenoreceptor agonist 6-allyl-2-amino-5,6,7,8tetrahydro-4H-thiazolo-(4,5-d)azepin hydrochloride (BHT 920), thus supporting a role for increased endothelium-dependent vasodilatory mechanisms in regulating the coronary circulation in $\mathrm{CHF}$.

The current investigation was designed to extend these previous studies and to determine if enhancement of endothelium-dependent relaxations in vitro in experimental $\mathrm{CHF}$ is specific to the coronary circulation, and secondly, to determine if endothelium-dependent relaxations in the coronary circulation are altered to other agonists. Thirdly, we sought to elucidate the mechanism underlying the enhanced alpha $a_{2}$-adrenergic endothelium-dependent relaxations, testing the hypothesis that this augmented coronary vascular response is mediated by nitric oxide (NO) and involves a guanine nucleotide-binding regulatory protein (G-protein ) mechanism.

\section{Methods}

Experiments were performed in two groups of mongrel dogs (18-27 $\mathrm{kg}$ ) that were fed standard diet and allowed free access to water. Dogs that had not been operated on served as the control group. To produce experimental CHF, dogs underwent rapid ventricular pacing for $15 \mathrm{~d}$. This time period of pacing consistently produces a hemodynamic and neurohumoral state of severe $\mathrm{CHF}(10)$.

Model of experimental CHF. Dogs in the CHF group underwent implantation of a permanent pacemaker $5 \mathrm{~d}$ before the onset of pacing. Under pentobarbital anesthesia ( $30 \mathrm{mg} / \mathrm{kg}$ intravenously [iv]), a left thoracotomy incision was made at the fourth intercostal space, the heart was exposed, the pericardium was opened, and a screw-in epicardial pacemaker lead was attached to the right ventricular myocardium. The pacemaker lead was connected to a generator implanted subcutaneously (5320; Medtronic Inc., Minneapolis, MN). The incision was closed and the dogs were allowed to recover for $5 \mathrm{~d}$, during the first $3 \mathrm{~d}$ of which they received prophylactic clindamycin (Upjohn, Barceloneta, PR) and Combiotic ${ }^{\mathbf{R}}$ (Pfizer Inc., New York, NY). All protocols were reviewed and approved by the Animal Care and Use Committee of the Mayo Clinic and Foundation. All animals were under the care of the Department of Veterinary Medicine throughout the course of the study.

On the fifth postoperative day, each pacemaker was programmed to 250 beats per minute (bpm) and continued at this rate for $15 \mathrm{~d}$.

Hemodynamic measurements. Dogs in the CHF group were anesthetized with pentobarbital sodium $(5-10 \mathrm{mg} / \mathrm{kg}$ iv) and fentanyl (Janssen, Piscataway, NJ) (0.007-0.008 mg/ kg iv), intubated, and artificially ventilated with supplemental oxygen at 4 liters/min on a respi- 
rator (Harvard Apparatus Inc., South Natick, MA). The right femoral artery was cannulated for measurement of systemic pressure and sampling of arterial blood. The right external jugular vein was cannulated with a flow-directed, balloon-tipped thermodilution pulmonary artery catheter (model 93-121A 7-French; American Edwards Laboratories, Santa Ana, CA) and was advanced into the pulmonary artery for measurement of cardiac filling pressures and determination of cardiac output. Hemodynamic data were collected and included mean arterial pressure (MAP), right atrial pressure (RAP), pulmonary capillary wedge pressure, and cardiac output $(\mathrm{CO})$. $\mathrm{CO}$ was measured by thermodilution technique and was determined by the average of four measurements. Systemic vascular resistance (SVR) was calculated from the formula: SVR = $($ MAP - RAP $) / C O$. Arterial blood for hormone assay was collected into EDTA tubes and was placed on ice immediately. After centrifugation at $2,500 \mathrm{rpm}$ at $4^{\circ} \mathrm{C}$ for $10 \mathrm{~min}$, the plasma was separated and stored at $-20^{\circ} \mathrm{C}$ until assay. Atrial natriuretic factor (ANF) was determined after extraction by RIA as previously described (11). Plasma renin activity (PRA) was determined by RIA as reported previously (12). At this point, the dogs were exsanguinated through the carotid artery. Control dogs received pentobarbital sodium $(30 \mathrm{mg} / \mathrm{kg}$ iv) and were exsanguinated through the carotid artery.

In vitro experiment. The heart, renal, and femoral arteries were removed and placed in a chilled, modified Krebs-Ringer bicarbonate solution (control solution) of the following composition (mM): $\mathrm{NaCl}$ 118.3, $\mathrm{KCl} 4.7, \mathrm{CaCl}_{2} 2.5, \mathrm{MgSO}_{4} 1.2, \mathrm{KH}_{2} \mathrm{PO}_{4}$ 1.2, $\mathrm{NaHCO}_{3} 25.0$, CaEDTA 0.026 , and glucose 11.1 . The left circumflex coronary artery was dissected from the heart. Then the arteries were cleaned of connective tissue, with care taken not to touch the luminal surface, and were cut into rings $5 \mathrm{~mm}$ in length. Some rings were denuded of endothelium by inserting a pair of fine forceps into the lumen and gently rolling the ring back and forth on Krebs-Ringer-wetted paper. Rings of coronary, femoral, and renal arteries, with and without endothelium, from a single $\mathrm{dog}$ were studied in parallel. Each ring was mounted between a fixed point and a force transducer (UC-2; Gould Inc., Glen Bournie, MD) for measurement of isometric force (model 7418A recorder; Hewlett-Packard Co., Palo Alto, CA) in an organ bath filled with $25 \mathrm{ml}$ of the buffered salt solution at $37^{\circ} \mathrm{C}$ and was gassed with $95 \% \mathrm{O}_{2}-5 \%$ $\mathrm{CO}_{2}$. Each ring was progressively stretched to the optimal point on its length-tension curve, as determined by the active tension developed to potassium chloride $20 \mathrm{mM}$.

After a 30-min equilibration period, a cumulative concentrationresponse curve to $\mathrm{PGF}_{2}$ alpha $\left(10^{-8}-10^{-5} \mathrm{M}\right)$ was obtained. To study endothelium-dependent relaxations, the vessels were then contracted with $\mathrm{PGF}_{2}$ alpha $\left(2 \times 10^{-6} \mathrm{M}\right)$. Relaxations were studied in one of two separate sequences: acetylcholine, calcium ionophore A23187, and nitric oxide; or BHT 920 (13), and ADP. After each cumulative concentration-response curve, the tissues were washed at least three times with the control solution, and at least $30 \mathrm{~min}$ were allowed to elapse before the next drug was used.

To study the mechanism of enhanced endothelium-dependent relaxation to alpha ${ }_{2}$-adrenergic stimulation in coronary arteries, relaxations to BHT 920 and A23187 were tested in either the absence or presence of indomethacin $\left(10^{-5} \mathrm{M}, 60 \mathrm{~min}\right)$ alone, indomethacin $\left(10^{-5} \mathrm{M}, 60 \mathrm{~min}\right)$ plus pertussis toxin $(100 \mathrm{mg} / \mathrm{ml}, 120 \mathrm{~min})$, or indomethacin $\left(10^{-5} \mathrm{M}, 60 \mathrm{~min}\right)$ plus $N^{\mathrm{G}}$ monomethyl-L-arginine (LNMMA, $\left.10^{-4} \mathrm{M}, 60 \mathrm{~min}\right)$.

Drugs. The following drugs were used: acetylcholine, adenosine diphosphate, calcium ionophore A23187, indomethacin, pertussis toxin, $\mathrm{PGF}_{2}$ alpha (Sigma Chemical Co., St. Louis, MO), BHT 920 (Boehringer Ingelheim Pharmaceuticals, Inc., Ridgefield, CT), and LNMMA (Calbiochem-Novabiochem Corp., La Jolla, CA). Drugs were prepared daily in distilled water and were kept refrigerated at $4^{\circ} \mathrm{C}$ until use. Concentrations of the drugs are reported as the final molar concentration in the organ bath.

Preparation of nitric oxide. A gas bulb fitted with a silicon rubber injection septum was filled with NO from a cylinder (Union Carbide, Chicago, IL). An appropriate volume $(10-1,000 \mu \mathrm{l})$ was removed with a syringe and was injected into another gas bulb filled with $100 \mathrm{ml}$ of distilled water, which had been gassed with helium for $3 \mathrm{~h}$, giving stock solutions of NO of $4 \times 10^{-5} \mathrm{M}$ and $4 \times 10^{-4} \mathrm{M}$.

Statistical analysis. In the in vitro experiments, $n$ equals the number of rings taken from different dogs. The results are expressed as means \pm SEM. When rings with and without endothelium from a single dog were tested in parallel, Student's $t$ test for paired observations was used. When responses from different dogs were compared, an analysis of variance for one-way classification was used. Where appropriate, the effective concentration required to produce 10 or $50 \%$ of a maximal response $\left(\mathrm{ED}_{10}, \mathrm{ED}_{50}\right)$ was calculated for the individual concentration-response curves, and the mean of these values is reported as the negative log of the molar concentration. Values were considered to be statistically significant when $P<0.05$.

\section{Results}

HEMODYNAMIC AND HORMONAL PARAMETERS

The hemodynamic parameters and hormonal values from the CHF group are compared to a control group in Table I. MAP and $\mathrm{CO}$ were significantly reduced in $\mathrm{CHF}$ in association with characteristic elevations in left and right atrial filling pressures. Calculated SVR was increased in CHF and elevation of circulating ANF and PRA occurred.

\section{GENERAL RESPONSIVENESS OF VESSELS}

There were no differences between groups in the resting tension of coronary or renal arteries, with or without endothelium, at the optimal point on their length-tension curve (Table II). However, femoral arteries with endothelium had a lower resting tension in $\mathrm{CHF}$ compared with control. In $\mathrm{CHF}, \mathrm{ED}_{50}$ for $\mathrm{PGF}_{2}$ alpha of arteries with endothelium were similar to control values for that artery (Table III); removal of the endothelium resulted in a small but statistically significant increase in sensitivity to this agonist. Maximal tension developed to $\mathrm{PGF}_{2}$ alpha (Table III) did not differ in CHF compared with control.

\section{Endothelium-dependent responses}

ACETYLCHOLINE

In all arteries, acetylcholine produced concentration-dependent relaxations of rings with endothelium (Fig. 1, $A-C$ ). In coronary arteries (Fig. $1 \mathrm{~A}$ ), the threshold for relaxation occurred at significantly lower concentrations during CHF compared with control ( $-\log \mathrm{ED}_{-10}$ : control $8.3 \pm 0.1$ vs $\mathrm{CHF}$ $8.7 \pm 0.1 ; n=6, P<0.05)$. CHF did not significantly alter the responses of femoral or renal arteries (Fig. 1, $B$ and $C$ ) from those seen in control vessels.

Table I. Hemodynamic and Hormonal Measurements in Control and CHF Dogs

\begin{tabular}{lcc}
\hline & Control & CHF \\
\hline MAP $(\mathrm{mmHg})$ & $120 \pm 2$ & $69 \pm 6^{*}$ \\
RAP $(\mathrm{mmHg})$ & $1.7 \pm 0.5$ & $8.5 \pm 1.0^{*}$ \\
LAP $(\mathrm{mmHg})$ & $7.8 \pm 0.7$ & $15.2 \pm 1.0^{*}$ \\
CO (liter/min) & $3.3 \pm 0.21$ & $1.3 \pm 0.2^{*}$ \\
SVR (resistance units) & $35.0 \pm 3.0$ & $52.2 \pm 5.4^{*}$ \\
PRA (ng/ml per $h)$ & $2.5 \pm 1.4$ & $8.5 \pm 1.1^{*}$ \\
ANF $(\mathrm{pg} / \mathrm{ml})$ & $62 \pm 7$ & $508 \pm 52^{*}$ \\
\end{tabular}

Values are means \pm SEM.

LAP, left atrial pressure; Control, $n=5$; CHF, $n=4$.

${ }^{*} P<0.05 \mathrm{CHF}$ vs control. 
Table II. Tension of Coronary, Femoral, and Renal Arteries at Optimal Point on Length-Tension Curve

\begin{tabular}{lcc}
\hline Artery & With endothelium & Without endothelium \\
\hline & $g$ & $g$ \\
Coronary & & \\
Control & $11.0 \pm 1.7$ & $9.3 \pm 1.1$ \\
CHF & $11.8 \pm 1.0$ & $10.4 \pm 0.7$ \\
Femoral & & \\
Control & $15.3 \pm 1.2$ & $16.3 \pm 1.4$ \\
CHF & $11.6 \pm 0.8^{*}$ & $13.5 \pm 1.2$ \\
Renal & & \\
Control & $15.7 \pm 1.2$ & $13.2 \pm 1.2$ \\
CHF & $12.6 \pm 1.7$ & $12.1 \pm 1.8$ \\
\hline
\end{tabular}

Values are means \pm SEM

$n=6$ in all groups.

$* P<0.05$ CHF vs control.

BHT 920

With endothelium. BHT 920 produced concentration-dependent relaxations of coronary arteries. In CHF, there was a marked increase in endothelium-dependent relaxation of coronary arteries as compared with control (maximal relaxation: control $[n=6]-15 \pm 9 \%$ vs CHF $[n=5]-92 \pm 5 \% ; P<0.05$ ) (Fig. 2). In contrast, in rings of femoral artery contracted to equivalent levels of tension by $\mathrm{PGF}_{2}$ alpha, BHT 920 produced only slight relaxation which was not different in CHF compared with control (maximal relaxation: control [ $n=3]$ $-5 \pm 1 \%$ vs $\mathrm{CHF}$ [ $n=5]-6 \pm 7 \%$ ). In renal arteries (Fig. 3 ), while a small contraction of control vessels occurred, there was a relaxation of $\mathrm{CHF}$ vessels; the maximal change in tension in CHF $(-13 \pm 5 \%)$ was not different from control $(9 \pm 10 \%)(P$ $=$ NS). However, an analysis of the area under the curve revealed a significant difference between the $\mathrm{CHF}$ and control arteries (area under the curve: control $28 \pm 19$ vs CHF $-36 \pm 15$; $P<0.05)$.

Table III. Response to Prostaglandin $F_{2}$ alpha in Coronary, Femoral, and Renal Arteries

\begin{tabular}{lccccc}
\hline & \multicolumn{2}{c}{$\begin{array}{c}E_{\text {so }} \\
-\log \mathrm{M}\end{array}$} & & \multicolumn{2}{c}{ Maximal tension* } \\
\cline { 2 - 3 } \cline { 5 - 6 } Group & $\begin{array}{c}\text { With } \\
\text { endothelium }\end{array}$ & $\begin{array}{c}\text { Without } \\
\text { endothelium }\end{array}$ & & $\begin{array}{c}\text { With } \\
\text { endothelium }\end{array}$ & $\begin{array}{c}\text { Without } \\
\text { endothelium }\end{array}$ \\
\hline Coronary & & & & & \\
Control & $6.0 \pm 0.1$ & $6.3 \pm 0.1^{\ddagger}$ & & $13.8 \pm 1.6$ & $15.6 \pm 1.7$ \\
CHF & $6.1 \pm 0.1$ & $6.3 \pm 0.1^{\ddagger}$ & & $9.7 \pm 1.8$ & $11.4 \pm 0.9$ \\
Femoral & & & & \\
Control & $5.8 \pm 0.1$ & $6.1 \pm 0.1$ & & $18.4 \pm 2.8$ & $23.6 \pm 2.0$ \\
CHF & $5.8 \pm 0.1$ & $5.9 \pm 0.1$ & & $16.0 \pm 3.1$ & $22.0 \pm 3.4$ \\
Renal & & & & \\
Control & $5.9 \pm 0.1$ & $6.1 \pm 0.1$ & & $31.7 \pm 2.6$ & $30.0 \pm 3.1$ \\
CHF & $5.9 \pm 0.2$ & $5.9 \pm 0.1$ & & $21.3 \pm 5.6$ & $28.8 \pm 7.0$ \\
\hline
\end{tabular}

Values are means \pm SEM.

$n=6$ in all groups.

* Grams of tension evoked by $\mathrm{PGF}_{2}$ alpha $10^{-5} \mathrm{M}$.

${ }^{\ddagger} P<0.05$ arteries without compared to with endothelium.
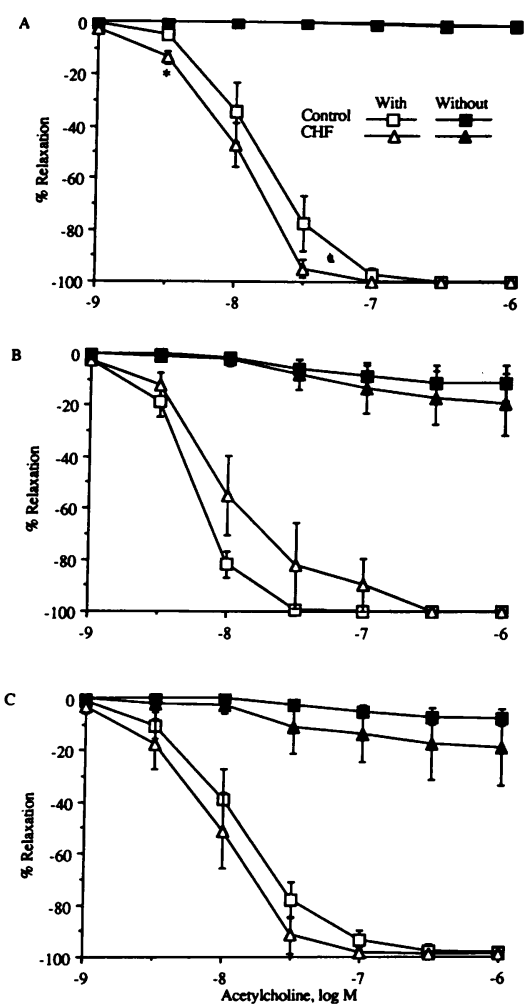

Figure 1. Cumulative concentration-response curves to acetylcholine in coronary $(A) n=6$, femoral $(B) n=6$, and renal $(C) n=5$ arteries from control and $\mathrm{CHF}$ groups. With, with endothelium; Without, without endothelium Data are presented as percent relaxation (means \pm SEM) from a contraction to prostaglandin $F_{2}$ alpha (2 $\times 10^{-6} \mathrm{M}$ ); vessels with endothelium: coronary: control, $10.2 \pm 1.3 \mathrm{~g}$ CHF, $6.4 \pm 0.9$ g. femoral: control, $12.2 \pm 2.0$ g; CHF, $9.5 \pm 2.6 \mathrm{~g}$. renal: control, $26.4 \pm 2.5$ $\mathrm{g}$; CHF, $17.9 \pm 6.0 \mathrm{~g} ; P$ $=$ NS. ${ }^{*} P<0.05$, percent relaxation $\mathrm{CHF}$ vs control.

Without endothelium. In each artery studied, when the endothelium was removed BHT produced a contraction which did not differ in CHF from control (Figs. 2 and 3; femoral data not shown).

\section{Adenosine diphosphate}

ADP produced concentration-dependent relaxations of all arteries, which were greater in rings with endothelium than in rings without endothelium. When relaxations to ADP of arteries with endothelium (Table IV) and without endothelium (data not shown) in CHF were compared with control, no

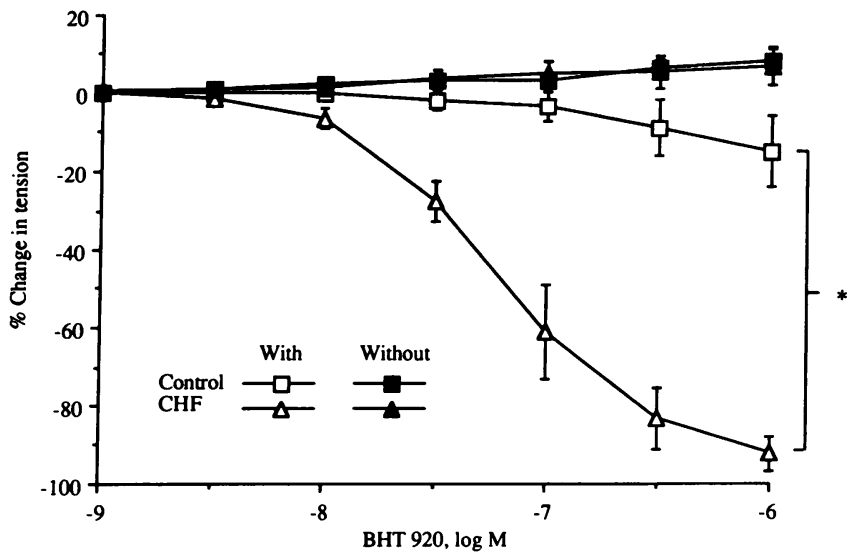

Figure 2. Cumulative concentration-response curves to BHT 920 in coronary arteries from control and CHF groups. With, with endothelium; Without, without endothelium. Data are presented as percent change in tension (means \pm SEM) from a contraction to prostaglandin $\mathrm{F}_{2}$ alpha $\left(2 \times 10^{-6} \mathrm{M}\right)$; vessels with endothelium: control $(n=6)$ $11.4 \pm 1.3 \mathrm{~g}$ vs $\mathrm{CHF}(n=5) 8.8 \pm 1.8 \mathrm{~g} ; P=\mathrm{NS} .{ }^{*} P<0.05$ change in tension to $10^{-6} \mathrm{M}$ in $\mathrm{CHF}$ vs control. 


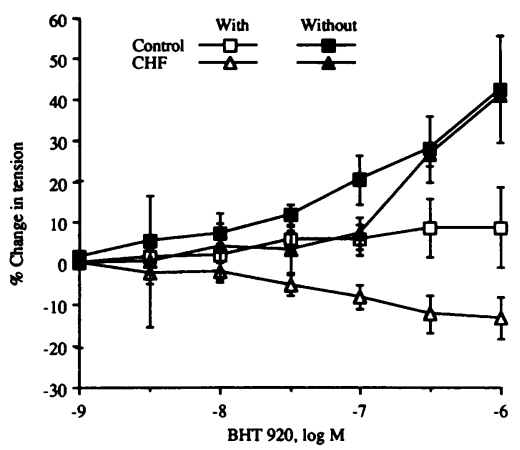

Figure 3. Cumulative concentration-response curves to BHT 920 in renal arteries from control and CHF groups. With, with endothelium; Without, without endothelium. Values represent percent change in tension (means \pm SEM) from a contraction to prostaglandin $\mathrm{F}_{2}$ alpha $(2$ $\left.\times 10^{-6} \mathrm{M}\right)$; vessels with endothelium: control $21.9 \pm 3.0 \mathrm{~g}$ vs CHF $21.8 \pm 5.2 \mathrm{~g} ; n=5 ; P=\mathrm{NS}$. The area under the curve for CHF rings with endothelium was statistically different from that of control rings with endothelium, $P<0.05$.

differences among coronary, femoral, or renal arteries were found.

\section{A23187}

The calcium ionophore A23187 produced concentration-dependent relaxations of arteries with endothelium, but no response in rings without endothelium. In response to A23187, there were no differences in endothelium-dependent relaxations in coronary, femoral, or renal arteries (Table IV).

\section{Nitric oxide}

Relaxations to the endothelium-derived relaxing factor nitric oxide were tested in rings from which the endothelium had been removed (Fig. 4, $A-C$ ). Responses in CHF were not different from control for coronary or renal arteries; there was a tendency to decreased sensitivity of femoral arteries to NO in CHF (Ed-50: control $7.0 \pm 0.1$ vs CHF $6.4 \pm 0.3 ; P=\mathrm{NS}$ ).

\section{Mechanism of Enhanced BHT 920 Response in Coronary Arteries}

RESTING TENSION

In both control (Fig. $5 A$ ) and CHF (Fig. $5 B$ ) rings, resting tension of coronary arteries with endothelium increased slightly after indomethacin. In control rings (Fig. $5 \mathrm{~A}$ ), the addition of L-NMMA produced a further increase in resting

Table IV. Endothelium-dependent Relaxations to ADP and A23187 Expressed as $E D_{-50}(-\log M)$

\begin{tabular}{lccc}
\hline & Coronary & Femoral & Renal \\
\hline ADP & & & \\
Control & $7.0 \pm 0.1(n=6)$ & $6.1 \pm 0.1(n=6)$ & $6.2 \pm 0.1(n=6)$ \\
CHF & $7.1 \pm 0.1(n=5)$ & $6.1 \pm 0.2(n=3)$ & $6.3 \pm 0.0(n=3)$ \\
A23187 & & & \\
Control & $7.8 \pm 0.1(n=6)$ & $7.6 \pm 0.1(n=6)$ & $7.7 \pm 0.1(n=5)$ \\
CHF & $7.8 \pm 0.0(n=6)$ & $7.2 \pm 0.2(n=6)$ & $7.4 \pm 0.1(n=5)$
\end{tabular}

Values are $\mathrm{ED}_{-50}$ (means $\pm \mathrm{SEM}$ ) for $\mathrm{ADP}$ and $\mathrm{A} 23187$ from a contraction to prostaglandin $F_{2}$ alpha $\left(2 \times 10^{-6} \mathrm{M}\right)$ of arteries with endothelium. For each artery, maximal contractions to $\mathrm{PGF}_{2}$ alpha did not differ in $\mathrm{CHF}$ compared with control. Relaxations of vessels without endothelium did not differ in CHF compared with control and are not shown.
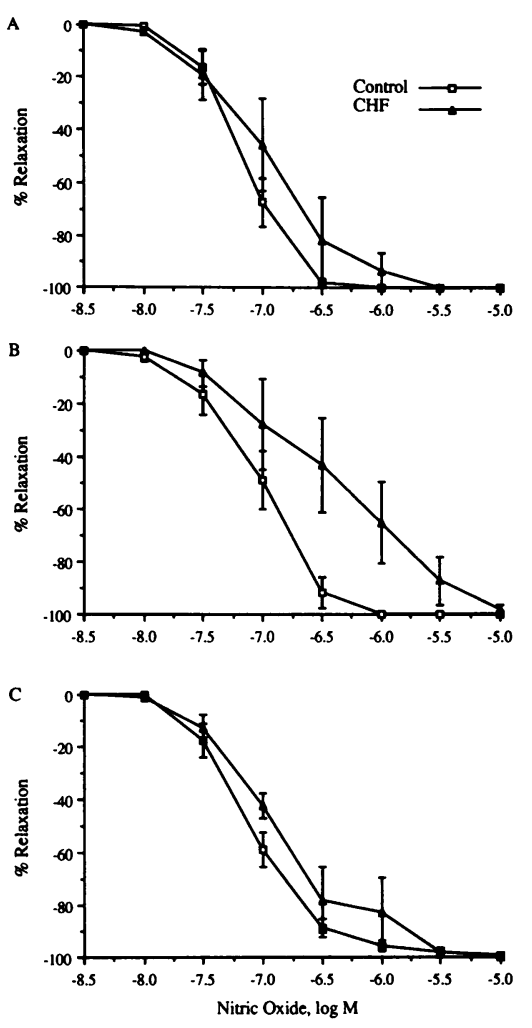

Figure 4. Cumulative concentration-response curves to the endothelium-derived relaxing factor, nitric oxide, in coronary $(A)$, femoral $(B)$, and renal $(C)$ arteries from which the endothelium was removed (control $n=6$, CHF $n=5$ ). Values represent percent relaxation (means \pm SEM) from a contraction to prostaglandin $\mathrm{F}_{2}$ alpha $\left(2 \times 10^{-6} \mathrm{M}\right)$. Coronary: control, $9.4 \pm 0.9$ g; CHF, $6.9 \pm 1.1 \mathrm{~g}$; femoral: control, $13.0 \pm 2.0$ g; CHF, $14.6 \pm 3.7 \mathrm{~g}$; renal: control, $19.7 \pm 2.0$ $\mathrm{g}$; CHF, $20.9 \pm 7.6 \mathrm{~g} ; P$ $=$ NS.

tension to a level not significantly greater than after indomethacin alone. In CHF (Fig. $5 \mathrm{~B}$ ), however, resting tension after L-NMMA and indomethacin significantly exceeded that seen with indomethacin alone. Indomethacin significantly increased the resting tension of both control (Fig. $6 A$ ) and CHF (Fig. $6 B$ ) coronary arteries without endothelium. After LNMMA, there was a further slight increase in tension in both groups which did not approach significance. Incubation of rings with indomethacin and pertussis toxin did not change resting tension of any artery when compared with indomethacin alone (data not shown).

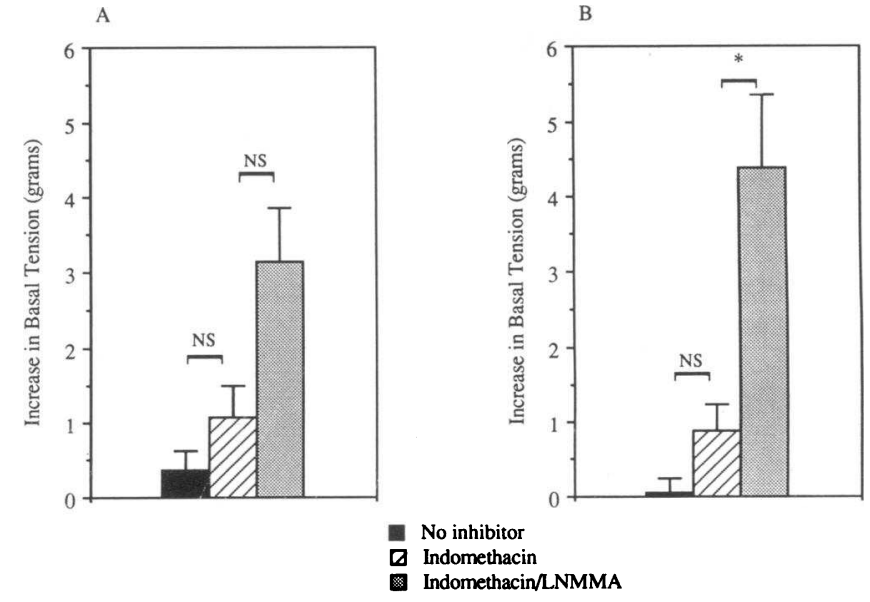

Figure 5. Change in resting tension (grams) of rings of coronary artery with endothelium from control $(A)$ and $\mathrm{CHF}(B)$ dogs in the absence of inhibitors or in the presence of indomethacin or indomethacin plus L-NMMA. Incubation time was $60 \mathrm{~min} .{ }^{*} P<0.05$ indomethacin plus L-NMMA vs indomethacin. 


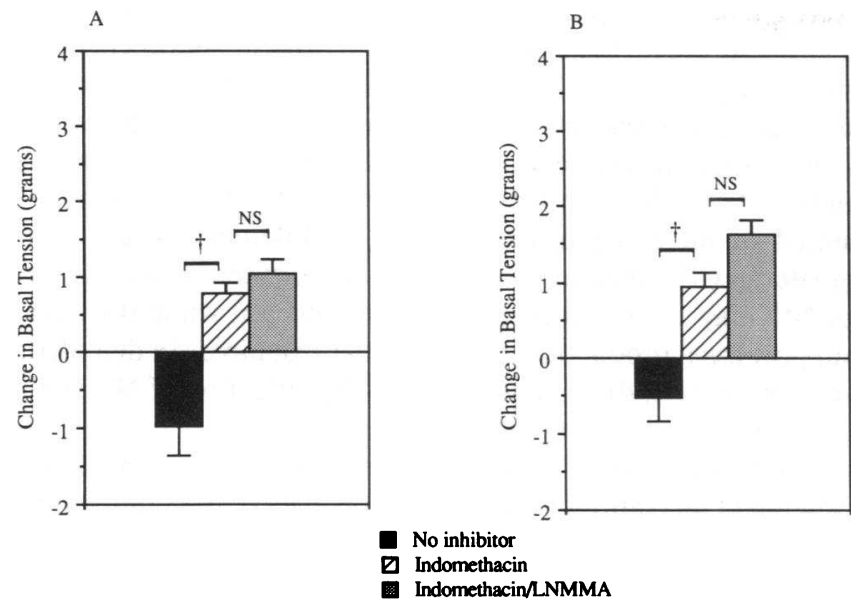

Figure 6. Change in resting tension (grams) of rings of coronary artery without endothelium from control $(A)$ and $\mathrm{CHF}(B)$ dogs in the absence of inhibitors or in the presence of indomethacin or indomethacin plus L-NMMA. Incubation time was 60 min. ${ }^{\dagger} P<0.05$ indomethacin vs no inhibitor.

\section{BHT 920}

In control arteries, indomethacin did not significantly reduce relaxations to BHT 920. However, indomethacin in combination with either pertussis toxin or L-NMMA eliminated the relaxations to this agonist (Fig. $7 \mathrm{~A}$ ). During CHF, indomethacin did not significantly reduce endothelium-dependent relaxations of coronary arteries to BHT 920 (Fig. 7 B). The addition of L-NMMA, however, reduced the maximal relaxation from $-86 \pm 7 \%$ (no inhibitor) to $-15 \pm 4 \%$ (indomethacin plus LNMMA $)(P<0.05)$. Similarly, the addition of pertussis toxin almost abolished the response: $-86 \pm 7 \%$ (no inhibitor) vs $-7 \pm 5 \%$ (indomethacin plus pertussis toxin, $P<0.05$ ). Re-

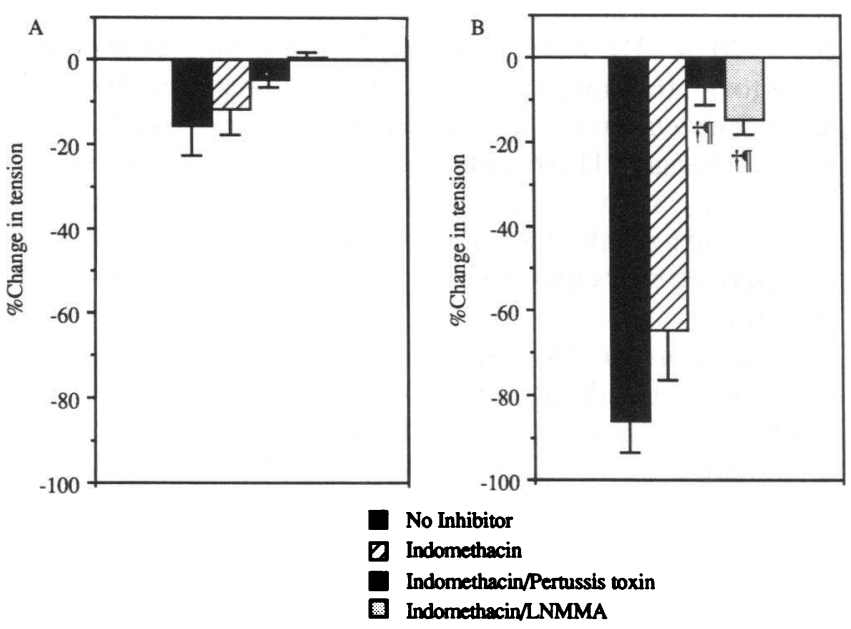

Figure 7. Maximal relaxation to BHT $920\left(10^{-6} \mathrm{M}\right)$ in coronary arteries with endothelium from control $(A)$ and $\mathrm{CHF}(B)$ in four experimental groups: no inhibitor, indomethacin $\left(10^{-5} \mathrm{M}\right)$, indomethacin $\left(10^{-5} \mathrm{M}\right)$ plus pertussis toxin $(100 \mathrm{mg} / \mathrm{ml})$, and indomethacin $\left(10^{-5} \mathrm{M}\right)$ plus L-NMMA $\left(10^{-4} \mathrm{M}\right)$. Values represent percent change in tension (means \pm SEM) from a contraction to $\mathrm{PGF}_{2}$ alpha $\left(2 \times 10^{-6}\right.$ $\mathrm{M})$. For each artery, contractions to $\mathrm{PGF}_{2}$ alpha did not differ between experimental groups; $n=6$ in all groups. ${ }^{\dagger} P<0.05$ vs no inhibitor; ' $P<0.05$ vs indomethacin.
Table V. Endothelium-dependent Relaxations to A23187 in Coronary Expressed as $E D_{-s o}(-\log M)$

\begin{tabular}{lll}
\hline & Control & \multicolumn{1}{c}{ CHF } \\
\hline No inhibitor & $7.8 \pm 0.0$ & $7.8 \pm 0.0$ \\
Indomethacin & $7.7 \pm 0.1$ & $7.8 \pm 0.1$ \\
Indomethacin/pertussis toxin & $7.7 \pm 0.1$ & $7.8 \pm 0.1$ \\
Indomethacin/L-NMMA & $7.3 \pm 0.0^{*} \ddagger \S$ & $7.5 \pm 0.1^{*} \ddagger \S \|$ \\
\hline
\end{tabular}

Values are $\mathrm{ED}_{-50}$ (means $\pm \mathrm{SEM}$ ) for $\mathrm{A} 23187$ of coronary arteries with endothelium in control and $\mathrm{CHF}$ from the four experimental groups: no inhibitor, indomethacin $\left(10^{-5} \mathrm{M}\right)$, indomethacin $\left(10^{-5} \mathrm{M}\right)$ plus pertussis toxin, $(100 \mathrm{mg} / \mathrm{ml})$, and indomethacin $\left(10^{-5} \mathrm{M}\right)$ plus $\mathrm{L}$ NMMA $\left(10^{-4} \mathrm{M}\right)$. Vessels were contracted with $\mathrm{PGF}_{2}$ alpha $\left(2 \times 10^{-6}\right.$; for each artery, contractions to $\mathrm{PGF}_{2}$ alpha did not differ between experimental groups).

${ }^{*} P<0.05$ vs no inhibitor; $¥ P<0.05$ vs indomethacin; $\S P<0.05$ vs indomethacin/pertussis toxin; $\| P<0.05$ vs control. $n=6$ in all groups.

sponses to BHT 920 in arteries without endothelium were not altered (data not shown).

A23187

Non-receptor-mediated endothelium-dependent relaxations in control and CHF coronary arteries are shown in Table V. Within both groups, the addition of indomethacin with or without pertussis toxin did not alter the sensitivity of coronary arteries to A23187. L-NMMA produced a significant shift to the right in the concentration-response curve to the calcium ionophore in both groups which, however, was less in CHF than in control.

\section{Discussion}

The major finding of this study is that endothelium-dependent relaxations are affected heterogeneously in CHF. Specifically, alpha ${ }_{2}$-adrenergic pathways of endothelium-dependent relaxation are enhanced in the coronary circulation, and to a lesser magnitude in the renal circulation, while other mechanisms are essentially unchanged. This enhancement is mediated by increased production of nitric oxide through a pertussis toxinsensitive pathway.

In human and experimental congestive heart failure, optimal circulatory homeostasis is achieved by a delicate balance of vasoconstrictor and vasodilator mechanisms. Activation of catecholamines (14), the renin-angiotensin-aldosterone system (15), vasopressin (16), and endothelin (17) promote vasoconstriction which is balanced by endogenous vasodilator forces such as prostaglandin (18) and atrial and brain natriuretic peptides $(11,19)$. In severe $\mathrm{CHF}$, vasoconstrictor mechanisms predominate with elevation of systemic vascular resistance in association with renal, splanchnic, and cutaneous vasoconstriction $(1,20)$ and impaired peripheral vasodilation (21). However, coronary blood flow is preserved (1-4) and coronary vascular resistance may be reduced $(2,4)$. The results of our study demonstrate that enhancement of a local vasodilator mechanism, namely alpha ${ }_{2}$-adrenergic receptor-mediated endothelium-dependent relaxation, occurs in the coronary but not femoral artery in experimental CHF. Thus, this alteration of local endogenous vasodilator forces may, in a milieu of elevated circulating catecholamines (14), contribute to the preservation of 
coronary blood flow in CHF, as suggested by Main and coworkers (9). In addition, such vasodilatory mechanisms may also serve to preserve renal blood flow in CHF.

In this investigation and in that of Main et al. (9), endothelial responses were studied only in large epicardial conduit arteries and not resistance vessels. Therefore, caution should be exercised in extrapolating the results to the regulation of coronary blood flow by the coronary microcirculation. Secondly, differential regulation of large conduit arteries as compared with the microcirculation may occur in $\mathrm{CHF}$, as noted in the preliminary studies of Bank et al. (22), which demonstrated an intact endothelial response in large arteries of the human forearm as compared with an impaired response in the microcirculation. Differences in endothelium-dependent relaxations between arteries from control and CHF animals are probably not due to differences in contractions to $\mathrm{PGF}_{2}$ alpha as these were similar from both groups of dogs. Decreased sensitivity to the prostanoid in coronary arteries with endothelium may be due to basal release of endothelium-derived relaxing factor.

Using acetylcholine, a depression of endothelium-dependent relaxation in CHF has been demonstrated in both human and animal models of CHF (5-8, 23-25). The present study examined responses to acetylcholine after $2 \mathrm{wk}$ of experimental $\mathrm{CHF}$ and found that the threshold for relaxation to acetylcholine was decreased significantly in coronary arteries but was unchanged in femoral and renal arteries. Increases in blood flow in canine systemic arteries result in augmented endothelium-dependent relaxations to acetylcholine (26) and studies, while controversial $(2,27)$, have demonstrated increased myocardial blood flow in CHF. A similar mechanism may operate to produce the augmented response to acetylcholine reported in this study. Additionally, an endothelium-derived hyperpolarizing factor (28) may be altered during CHF, but this mechanism was not evaluated in our study.

In contrast to the enhancement of responses to alpha $a_{2}$ adrenergic and muscarinic receptor stimulation seen in coronary arteries, endothelium-dependent relaxations to adenosine diphosphate, mediated by endothelial purinergic $\left(\mathrm{P}_{2}\right)$ receptors $(29,30)$ and the calcium ionophore A23187, which increases endothelial cytosolic calcium independently of receptors, were unchanged in CHF. In addition, responses of femoral and renal arteries to these agonists did not differ in CHF from control. Thus, the enhancement of endothelial vasodilator function appears to occur in association with specific pathways while others are unchanged. It is a significant negative finding that these responses were not impaired and provides further evidence against a generalized dysfunction of endothelium-dependent responses in experimental CHF.

The sensitivity of coronary and renal vascular smooth muscle to the major chemical form of endothelium-derived relaxing factor, namely NO (31), was unchanged during CHF. However, the tendency for a reduced sensitivity to NO seen in femoral arterial smooth muscle may play a role in regional vascular tone favoring the maintenance of coronary as opposed to peripheral blood flow. Such an impaired femoral vasodilator response in $\mathrm{CHF}$ is at variance with the observations of Kaiser et al. (25), which may, in part, be explained by differences in experimental preparation. It should also be noted that a decreased resting tension was noted in the femoral arteries in CHF. The mechanism of this is unclear but, in part, could be explained by the use of the anesthetic agents.

Neither maximal relaxation to BHT 920 nor resting tension were altered in the presence of indomethacin. While many substances stimulate the production and release of endothelial vasodilator prostanoids (18), it does not appear from this study that such a pathway is involved in the exaggerated response to alpha $_{2}$ stimulation of coronary arteries seen in CHF. The addition of L-NMMA to coronary arteries with endothelium resulted in increased resting tension, a difference which was greater in $\mathrm{CHF}$ than in control. This suggests that tonic release of NO may be increased in CHF. In contrast, while the data support basal production of inhibitory prostanoids in denuded smooth muscle, they do not support the induction of NO synthesis in coronary smooth muscle during $\mathrm{CHF}$.

In the presence of L-NMMA, the enhanced endotheliumdependent relaxations to BHT 920 seen in CHF were markedly reduced. Since the sensitivity to exogenously administered NO is not altered, these data demonstrate that enhanced stimulated release of NO is central to the mechanism of enhanced endothelium-dependent relaxations to alpha $a_{2}$-adrenergic stimulation in coronary arteries in CHF.

Alpha $_{2}$ and beta adrenoreceptors are closely coupled to adenylate cyclase $(32,33)$ by $\mathrm{G}$-proteins which inhibit $(\mathrm{Gi})$ or stimulate (Gs) the catalytic unit, respectively. Responses to beta-adrenergic agonists are diminished in human CHF (34), and while receptor downregulation occurs $(35,36)$, a defect in receptor-adenylate cyclase production of cAMP also occurs (37). Feldman et al. (38) found an increased level and functional activity of $\mathrm{Gi}$ in failing myocardium and suggested that receptor traffic through beta receptors coupled to $\mathrm{Gi}$ may be inhibited during CHF.

Alpha $_{2}$ receptor activation is closely coupled to $\mathrm{Gi}(32)$ and produces endothelium-dependent relaxation of canine coronary arteries to epinephrine and norepinephrine $(39,40)$. The exotoxin pertussis toxin produces ADP ribosylation and inactivation of Gi. Previous studies have demonstrated that pertussis toxin inhibits endothelium-dependent relaxation to alpha $a_{2}$ adrenergic stimulation in porcine coronary arteries (41). In this study, the markedly enhanced endothelium-dependent relaxations of coronary arteries produced by the alpha ${ }_{2}$-agonist BHT 920 in CHF were completely lost in the presence of pertussis toxin. In contrast, non-receptor-mediated, endotheliumdependent relaxations, as assessed by the response to A23187, were unchanged. These findings are analagous to those of Feldman et al. (38) with beta receptor-coupled Gi activity and suggest that a parallel increase in $\mathrm{Gi}$ functional activity coupled to alpha ${ }_{2}$ receptors may occur in canine coronary endothelium in $\mathrm{CHF}$.

In conclusion, these studies demonstrate a selective enhancement of endothelium-dependent relaxations to alpha $\mathbf{2}_{-}$ adrenergic receptor stimulation in canine coronary arteries in experimental CHF. This is not observed in femoral arteries and is only modestly seen in renal arteries. Significant changes in other mechanisms of endothelium-dependent relaxation were not observed, and vascular smooth muscle sensitivity to NO was not altered. The mechanism of this uniquely enhanced response may involve increased stimulated production of nitric oxide. Furthermore, it may operate through a pertussis toxinsensitive pathway and may reflect increased functional activity of endothelial alpha ${ }_{2}$ receptor-associated $\mathrm{Gi}$. These alterations of endothelial vasodilator function may represent an important homeostatic mechanism which, in the face of falling cardiac output, selectively contributes to the preservation of coronary blood flow. 


\section{Acknowledgments}

The authors thank Lawrence Aarhus and Kevin Rud for their technical assistance without which this study could not have proceeded.

This work was supported by National Institutes of Health grants HL-36634 and HL-07111, and by the Mayo Foundation. BHT 920 was a gift from Boehringer Ingelheim Pharmaceuticals, Inc., Ridgefield, CT.

\section{References}

1. Flaim, S. F., and W. J. Minteer. 1980. Ventricular volume overload alters cardiac output distribution in rats during exercise. J. Appl. Physiol. (Respir. Environ. Exercise Physiol.). 49:482-490.

2. Horwitz, L. D., G. C. Curry, R. W. Parkey, and F. J. Bonte. 1974. Effect of isoproterenol on coronary blood flow in primary myocardial disease. Circulation. 50:560-564.

3. Opherk, D., F. Schwarz, G. Mall, J. Manthey, D. Baller, and W. Kubler. 1983. Coronary dilatory capacity in idiopathic dilated cardiomyopathy: analysis of 16 patients. Am. J. Cardiol. 51:1657-1662.

4. Nitenberg, A., J. M. Foult, F. Blanchet, and S. Zouioueche. 1985. Multifactorial determinants of reduced coronary flow reserve after dipyridamole in dilated cardiomyopathy. Am. J. Cardiol. 55:748-754.

5. Kubo, S. H., T. S. Rector, A. J. Bank, R. E. Williams, and S. M. Heifetz. 1991. Endothelium-dependent vasodilation is attenuated in patients with heart failure. Circulation. 84:1589-1596.

6. Ontkean, M., R. Gay, and B. Greenberg. 1991. Diminished endotheliumderived relaxing factor activity in an experimental model of chronic heart failure. Circ. Res. 69:1088-1096.

7. Drexler, H., and W. Lu. 1992. Endothelial dysfunction of hindquarter resistance vessels in experimental heart failure. Am. J. Physiol. 262 ( Heart \& Circ. Physiol. 31):H1640-H1645.

8. Katz, S. D., L. Biasucci, C. Sabba, J. A. Strom, G. Jondeau, M. Galvao, S Solomon, S. D. Nikolic, R. Forman, and T. H. LeJemtel. 1992. Impaired endothelium-mediated vasodilation in the peripheral vasculature of patients with congestive heart failure. J. Am. Coll. Cardiol. 19:918-925.

9. Main, J. S., C. Forster, and P. W. Armstrong. 1991. Inhibitory role of the coronary arterial endothelium to alpha-adrenergic stimulation in experimental heart failure. Circ. Res. 68:940-946.

10. Perrella, M. A., T. R. Schwab, B. O'Murchu, M. M. Redfield, C.-M. Wei, B. S. Edwards, and J. C. Burnett, Jr. 1992. Cardiac atrial natriuretic factor during evolution of congestive heart failure. Am. J. Physiol. 262 ( Heart \& Circ. Physiol. $31): \mathrm{H} 1248-\mathrm{H} 1255$.

11. Burnett, J. C., Jr., P. C. Kao, D. C. Hu, D. W. Heser, D. Heubelin, J. P. Granger, T. J. Opgenorth, and G. S. Reeder. 1986. Atrial natriuretic peptide elevation in congestive heart failure in the human. Science (Wash. DC). 231:1145-1147.

12. Redfield, M. M., B. S. Edwards, M. D. McGoon, D. M. Heublein, L. L. Aarhus, and J. C. Burnett, Jr. 1989. Failure of atrial natriuretic factor to increase with volume expansion in acute and chronic congestive heart failure in the dog. Circulation. 80:651-657.

13. Flavahan, N. A., T. J. Rimele, J. P. Cooke, and P. M. Vanhoutte. 1984. Characterization of postjunctional alpha-1 and alpha-2 adrenoceptors activated by exogenous or nerve-released norepinephrine in the canine saphenous vein. $J$. Pharmacol. Exp. Ther. 230:699-705.

14. Thomas, J. A., and B. H. Marks. 1978. Plasma norepinephrine in congestive heart failure. Am. J. Cardiol. 41:233-243.

15. Dzau, V. J., W. S. Colucci, N. K. Hollenberg, and G. H. Williams. 1981. Relation of the renin-angiotensin-aldosterone system to clinical state in congestive heart failure. Circulation. 63:645-651.

16. Szatalowicz, V. L., P. E. Arnold, C. Chaimovitz, D. Bichet, T. Berl, and R. W. Schrier. 1981. Radioimmunoassay of plasma arginine vasopressin in hyponatremic patients with congestive heart failure. $N$. Engl. J. Med. 305:263-266.

17. Margulies, K. B., F. L. Hildebrand, Jr., A. Lerman, M. A. Perrella, and J. C. Burnett, Jr. 1990. Increased endothelin in experimental heart failure. Circulation. 82:2226-2230.

18. Dzau, V. J., M. Packer, L. S. Lilly, S. L. Swartz, N. K. Hollenberg, and G. H. Williams. 1984. Prostaglandins in severe congestive heart failure. $N$. Engl. J. Med. 310:347-352.

19. Wei, C.-M., L. L. Aarhus, V. M. Miller, and J. C. Burnett, Jr. 1993. Action of C-type natriuretic peptide in isolated canine arteries and veins. Am. J. Physiol. 264 (Heart \& Circ. Physiol. 33):H71-H73.
20. Donald, K. W. 1959. Exercise and heart disease. Br. Med. J. 4:985-994.

21. Zelis, R., D. T. Mason, E. Braunwald, M. Winterhalter, and C. King. 1968. A comparison of the effects of vasodilator stimuli on peripheral resistance vessels in normal subjects and in patients with congestive heart failure. J. Clin Invest. 47:960-970.

22. Bank, A. J., T. S. Rector, L. K. Tschumperlin, M. D. Kraemer, and S. H. Kubo. 1992. Endothelium-dependent vasodilation of conduit arteries is not impaired in patients with heart failure. Circulation. 86:I-50a. (Abstr.)

23. Hirooka, Y., T. Imaizumi, A. Takeshita, S. Ando, and S. Harada. 1992. Endothelial-dependent forearm vasodilation to intra-arterial acetylcholine is impaired in patients with heart failure. Circulation 82 (Suppl. III):III-591a. (Abstr.)

24. Treasure, C. B., J. A. Vita, D. A. Cox, R. D. Fish, J. B. Gordon, G. H. Mudge, W. S. Colucci, M. G. St. John Sutton, A. P. Selwyn, R. W. Alexander, and P. Ganz. 1990. Endothelium-dependent dilation of the coronary microvasculature is impaired in dilated cardiomyopathy. Circulation. 81:772-779.

25. Kaiser, L., R. C. Spickard, and N. B. Olivier. 1989. Heart failure depresses endothelium-dependent responses in canine femoral artery. Am. J. Physiol. 256 (Heart \& Circ. Physiol. 25):H962-H967.

26. Miller, V. M., L. L. Aarhus, and P. M. Vanhoutte. 1986. Modulation of endothelium-dependent responses by chronic alterations of blood flow. Am. $J$. Physiol. 251 (Heart \& Circ. Physiol. 20):H520-H527.

27. Weiss, M. B., K. Ellis, R. R. Sciacca, L. L. Johnson, D. H. Schmidt, and P. J. Cannon. 1976. Myocardial blood flow in congestive and hypertrophic cardiomyopathy: relationship to peak wall stress and mean velocity of circumferential fiber shortening. Circulation. 54:484-494.

28. Komori, K., R. R. Lorenz, and P. M. Vanhoutte. 1988. Effects of nitric oxide and acetylcholine on electrical and mechanical properties of the smooth muscle of the canine mesenteric artery. Am. J. Physiol. 255 (Heart \& Circ. Physiol. 24): $\mathrm{H} 207-\mathrm{H} 212$.

29. Pirotton, S., E. Raspe, D. Demolle, C. Erneux, and J. M. Boeynaems. 1987. Involvement of inositol 1,4,5-trisphosphate and calcium in the action of adenine nucleotides on aortic endothelial cells. J. Biol. Chem. 262:17461-17466.

30. Houston, D. S., J. T. Shepherd, and P. M. Vanhoutte. 1986. Aggregating human platelets cause direct contraction and endothelium-dependent relaxation of isolated canine coronary arteries. Role of serotonin, thromboxane $A_{2}$, and adenine nucleotides. J. Clin. Invest. 78:539-544.

31. Rees, D. D., R. M. J. Palmer, and S. Moncada. 1989. The role of endothelium-derived nitric oxide in the regulation of blood pressure. Proc. Natl. Acad. Sci. USA. 86:3375-3378.

32. Jakobs, K. H. 1985. Coupling mechanisms of alpha ${ }_{2}{ }^{-a d r e n o c e p t o r s . ~} J$. Cardiovasc. Pharmacol. 7(Suppl. 6):S109-S112.

33. Casey, P. J., and A. G. Gilman. 1988. G protein involvement in receptoreffector coupling. J. Biol. Chem. 263:2577-2580.

34. Bristow, M. R., R. Ginsburg, W. Minobe, R. S. Cubicciotti, W. S. Sageman, K. Lurie, M. E. Billingham, D. C. Harrison, and E. B. Stinson. 1982. Decreased catecholamine sensitivity and $\beta$-adrenergic-receptor density in failing human hearts. N. Engl. J. Med. 307:205-211.

35. Fowler, M. B., J. A. Laser, G. L. Hopkins, W. Minobe, and M. R. Bristow. 1986. Assessment of the $\beta$-adrenergic receptor pathway in the intact failing human heart: progressive receptor down-regulation and subsensitivity to agonist response. Circulation. 74:1290-1302.

36. Bristow, M. R., R. Ginsburg, V. Umans, M. Fowler, W. Minobe, R. Rasmussen, P. Zera, R. Menlove, P. Shah, S. Jamieson, and E. B. Stinson. 1986. $\beta 1^{-}$and $\beta 2^{-}$adrenergic receptor subpopulations in nonfailing and failing human ventricular myocardium: coupling of both receptor subtypes to muscle contraction and selective $\beta 1$ receptor down-regulation in heart failure. Circ. Res. 59:297309.

37. Feldman, M. D., L. Copelas, J. K. Gwathmey, P. Phillips, S. E. Warren, F. J. Schoen, W. Grossman, and J. P. Morgan. 1987. Deficient production of cyclic AMP: pharmacologic evidence of an important cause of contractile dysfunction in patients with end-stage heart failure. Circulation. 75:331-339.

38. Feldman, A. M., A. E. Cates, W. B. Veazey, R. E. Hershberger, M. R. Bristow, K. L. Baughman, W. A. Baumgartner, and C. Van Dop. 1988. Increase of the $40,000-\mathrm{mol}$ wt pertussis toxin substrate ( $G$ protein) in the failing human heart. J. Clin. Invest. 82:189-197.

39. Cocks, T. M., and J. A. Angus. 1983. Endothelium-dependent relaxation of coronary arteries by noradrenaline and serotonin. Nature (Lond.). 305:627630.

40. Angus, J. A., T. M. Cocks, and K. Satoh. 1986. Alpha ${ }_{2}^{-}$adrenoceptors and endothelium-dependent relaxation in canine large arteries. Br. J. Pharmacol. 88:767-777.

41. Shimokawa, H., N. A. Flavahan, and P. M. Vanhoutte. 1989. Natural course of the impairment of endothelium-dependent relaxations after balloon endothelium removal in porcine coronary arteries. Circ. Res. 65:740-753. 